\title{
A case of Menke's kinky hair disease
}

\section{S P Lamabadusuriya ${ }^{1}$, Nishadi Perera ${ }^{2}$}

Sri Lanka Journal of Child Health, 2001; 30: 78-9

(Key words: Menke's disease, kinky hair disease)

Menke's disease is a progressive neurodegenerative condition associated with the presence of abnormal characteristic hair; the hair is depigmented, kinky and friable ${ }^{1}$. Microscopic examination of the hair reveals several abnormalities such as depigmentation, fractures of the shaft (trichorrhexis nodosa) and twisting (pili torti). Feeding difficulties contribute to poor weight gain and severe mental retardation and optic atrophy are constant features of the disease. Low serum copper and caeruloplasmin levels have been documented consistently in this rare condition which is inherited in a sex-linked recessive manner.

\section{Case Report}

A ten month old boy from Matara presented with developmental delay, depigmented hair and excessive crying. He was the product of a non-consanguineous marriage and developmental delay was noted at about 5 months because of poor head control and absence of rolling. His vision and hearing were grossly intact. There was no family history of developmental delay or abnormalities of hair.

On examination, his weight was $8.6 \mathrm{~kg}$, length $71 \mathrm{~cm}$ and head circumference $44.5 \mathrm{~cm}$. He was found to have depigmented, kinky, friable scalp hair. The cheeks were chubby and he had a short neck. The skin was normal in colour. The optic discs were pale, muscle tone was increased and the knee jerks were very brisk. The cardiovascular and respiratory systems were normal and the liver was just palpable.

Because of the appearance of the hair and neurological signs, a provisional diagnosis of Menkes disease was made. (Figure 1)

At present he is 2 years and 4 months old and has a developmental age of about 3 months. He has been free of seizures. At present the hair is more pigmented than before but retains the kinky character.

\footnotetext{
${ }^{1}$ Professor of Paediatrics, Faculty of Medicine, Colombo, ${ }^{2}$ Senior Registrar, Lady Ridgeway Hospital, Colombo.
}

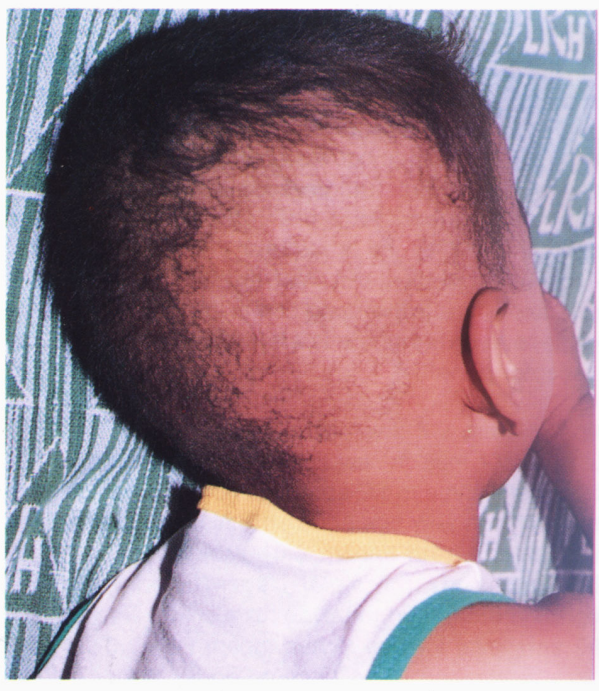

Figure 1. Depigmented, kinky scalp hair

\section{Investigations}

The full blood count was within normal limits. The chest x-ray and x-ray of the left wrist joint were normal. The urine was microscopically normal and was negative for phenylpyruvic acid. The serum caeruloplasmin level was $2.56 \mathrm{mg} / \mathrm{dl}$ (normal 16.8$34.2 \mathrm{mg} / \mathrm{dl}$ ) and serum copper level was $60 \mathrm{mg} / \mathrm{dl}$ (normal $80-150 \mathrm{mg} / \mathrm{dl}$ ). The hair shafts on microscopy revealed depigmentation, twisting and partial breaks of the shaft. (Figure 2)

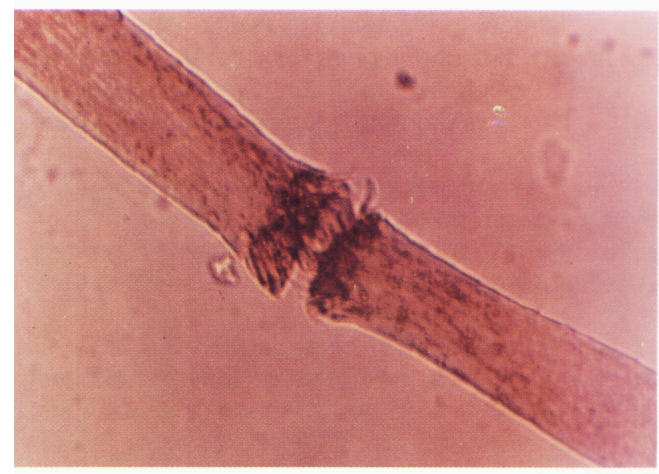

Figure 2. Hair shafts on microscopy 


\section{Discussion}

Menkes kinky hair disease is a very rare disorder not previously documented in Sri Lanka. The clinical diagnosis was made because of developmental delay, neurological signs and the characteristic macroscopic and microscopic appearance of the hair. The diagnosis was confirmed by finding very low serum caeruloplasmin and serum copper levels. Because low serum copper and caeruloplasmin levels have been found consistently in this rare condition, a defect in copper absorption and transport across the intestine has been postulated as the cause of this condition. Neuropathological changes that have been described include tortuous cerebral vessels secondary to defects in the intima, focal degeneration of the grey matter and marked changes in the cerebellum with loss of the internal granule cell layer and necrosis of the Purkinje cells.

Parenteral copper preparations (cupric acetate IV and copper histidinate subcutaneously) have been used in some patients with limited success. Some improvement has been reported if such therapy is started in the neonatal period ${ }^{2}$.

\section{Acknowledgements}

The authors wish to thank the Medical Illustration Unit of the Faculty of Medicine, Colombo for the photographs, Dr. Ranjith de Alwis of the Occupational Health Laboratory for serum copper studies and Mrs. Hemamali Pathmathilake for secretarial assistance.

\section{References}

1. Danks D M, Campbell P E, Stevens B J et al. Menkes kinky hair syndrome: An inherited defect in copper absorption with widespread effects. Pediatrics 1972; 50:188.

2. Behrman $\mathrm{R}$ E editor. Nelson Textbook of Pediatrics. Philadelphia; Saunders 1992; 1528. 
